\title{
COMMENT \\ Protecting children from known pesticides exposures: our collective duty to provide primary prevention
}

\author{
Nsedu Obot Witherspoon ${ }^{1}$ \\ Pediatric Research (2019) 85:118-119; https://doi.org/10.1038/s41390-018-0210-x
}

The growing amount of available peer-reviewed science indicates that there could be a linkage between exposure to pesticides, especially during early childhood development, and the diagnosis of Autism Spectrum Disorder (ASD) and Attention Deficit Syndrome (ADS). The Article "Children's Low Level Pesticide Exposure and Associations with Autism and ADHD: A Review" provides additional evidence of a mechanistic association through various research summaries. Additional research is called for to examine the link between exposures to pesticides at levels that do not cause acute toxicity but may be part of the multifactorial causes of ASD and ADHD. While additional research is always supported and necessary, those of us in the advocacy arena wonder how much additional science will be needed for action to occur? Our regulatory agencies need to take lessons from past mistakes to not protect our public's health and stop waiting for more children to be harmed.

The most common measure of agricultural pesticide use is pounds of active ingredients applied in a given year on an acre of crops. Pesticides use in the U.S. is most reported by the U.S. Department of Agriculture at the state level and nationally. Pesticide impact on human health and the environment is related to how widely and frequently a pesticide is applied. In the midwest, rather than a decrease in the production of pesticides, we are witnessing a greater use of three herbicides in particularglyphosate, 2,4-D, and dicamba. These are the herbicides most likely to increase the risk of adverse birth outcomes. This increase in use and exposures places vulnerable populations, such as children, at additional risk. The Children's Environmental Health Network (CEHN), a national non-profit organization committed to protecting all children from environmental hazards, is working with key partners to bring attention to this crisis and call for much needed attention to these known exposure routes.

An example of non-action to protect the public's health was provided by the former U.S. EPA Administrator who announced in March 2017 that the science on chlorpyfrifos was unresolved. Chlorpyrifos is a widely used and highly volatile neurotoxic chemical that studies have shown is harming the development of children's brains. Although the EPA banned residential use of chlorpyrifos in 2001, this pesticide is still widely used in agriculture. When mothers are exposed during pregnancy, their children are at higher risk of having lower IQs, developmental delays, and autism. ${ }^{1}$ At the time, previous plans to ban its use on food and crops were halted. This step was taken despite EPA's own scientists published an assessment of health risks in 2016 that found, through their diet, infants were being exposed to the pesticide at levels 140 times what could be considered safe. ${ }^{2}$
In August, a historic ruling in the San Francisco Superior Court found the Monsanto corporation (recently merged with Bayer) completely liable for health damages caused by its herbicide, Roundup. The plaintiff, DeWayne Johnson, was awarded \$289 million in damages. While, Mr. Johnson unfortunately continues to suffer from Non-Hodgkins Lymphoma, the implications of the verdict around the world have advanced important steps ahead to protect the public. Several countries have taken action against glyphosate and Roundup. Brazil is suspending use of the herbicide, Germany is aiming to end the use of glyphosate in this legislative period, Australia is considering suspending sales of the weedkiller and British business owners are discussing pulling the product from shelves.

Considering exposures through pesticide application indoors and surrounding grounds, we know that exposure of pesticides through residential use is another area deserving of serious attention. There are some protective policies around the country that take the evidence provided in research and translate the implications for the health and well-being of the public. Of the communities that they impact. Thanks to the collective work of the Columbia Center for Children's Environmental Health and WE ACT for Environmental Justice, in 2005 the New York City Council incorporated integrated pest management (IPM) into Local Law 37 , mandating the use of IPM in all city owned buildings. IPM is the economically safer practice of combining the knowledge of pests and pest control to manage the damage from pests while minimizing the impacts to human health and the environment. The New York Council credited the research from the Columbia Center on the exposure of pregnant women and newborns to pesticides as motivating the 2005 law. Then in 2007, the Center's research in public-housing, along with community partners, brought IPM into the passage of NYC Safe Housing Act by the New York City Council. This law requires more stringent remediation requirements for asthma triggers, including mold conditions and pest infestation. These actions of utilizing available science to inform public policy making not only helped tenants and advocates improve conditions for rental housing but also put New York at the forefront of safer pest control methods in the United States.

Looking further at the implications to children with ADHD diagnosis, the Learning Disabilities Association of America and the National Institute of Mental Health indicate that learning disabilities are found in $20-30 \%$ of those with this disorder. ${ }^{3}$ These realities place incredible stress upon the children and families involved. Children with symptoms of inattention may often overlook or miss details, make careless mistakes in

${ }^{1}$ Children's Environmental Health Network, Washington, DC, USA

Correspondence: Nsedu Obot. Witherspoon (nobotw@gmail.com)

Received: 27 August 2018 Accepted: 10 September 2018

Published online: 18 October 2018 
schoolwork, have problems organizing tasks, be constantly in motion, have trouble with patience, and witness anxiety. Children with $A D H D$ and their families require specific guidance and education to help in overcoming these challenges. Health equity questions also are up for consideration since ADHD prevalence is slightly higher among African Americans. Teachers are also important to engage in this support network for their benefit and that of their students.

Many children with ASD can exhibit social differences within the first year of life but skill loss, including language and social skills, progress rapidly around age two. ${ }^{4}$ These observations can come after some children appear to develop relatively typically up to that age. Implications to ASD can include sensitivities to the sensory environment, struggles to respond to and understand social aspects of a situation, exhibiting repetitive behavior, and challenges with organization and attention. Parenting skills training, stress management techniques, and support groups are all encouraged to assist families and support ADHD and ASD children in living to their full potential.

For all children living with these syndromes, the presence of appropriate supports in school, home, and community settingssupports based on the best available knowledge and on individual student needs-can create the context for students to meaningfully participate in school and in life.

Children who are diagnosed with ASD or ADHD require various levels of support and guidance to meet important achievements in the course of their lives. In many cases, these children continue to proposer and move forward in life. In other cases the journey through education alone is a very challenging one for these children and those that support them. Organizations such as the Children's Environmental Health Network (CEHN), a national nonprofit working for close to three decades to protect all children from harm, continue to push for the need to have and better use available science for the child-protective standards and policies that are necessary for their well-being. Pesticide Action Network (PAN) works daily to hold industries accountable and magnify the implications of pesticide exposures upon children, which are outlined in the report Generation in Jeopardy. The American Public Health Association (APHA) has a policy Affirming the Importance of Regulating Pesticide Exposures to Protect Public Health. The American Association of Poison Control Centers (AAPPC) received over 57,000 calls to their centers in 2016 related to unintended pesticide exposures in children under the age of six. ${ }^{5,6}$ These organizations and many other child health organizations advocate that new data and sharper science help target efforts, so that significant risk reduction to pesticides can be achieved much earlier than otherwise likely, and at lower social and economic cost to society as a whole.

\section{ADDITIONAL INFORMATION}

Competing interests: The author declares no competing interests.

Publisher's note: Springer Nature remains neutral with regard to jurisdictional claims in published maps and institutional affiliations.

\section{REFERENCES}

1. Pesticides and pregnancy. American Pregnancy Association. http:// americanpregnancy.org/pregnancy-health/pesticides/. Accessed 23 Aug 2018.

2. Revised Human Health Assessment of chlorpyrifos. U.S. Environmental Protection Agency. 2016. https://www.epa.gov/ingredients-used-pesticide-products/revisedhuman-health-risk-assessment-chlorpyrifos. Accessed 20 Aug 2018.

3. ADHD. Learning Disabilities Association of America. https://ldaamerica.org/typesof-learning-disabilities/adhd/

4. Feature Article on Supporting Success in School and Beyond for Students with Autism Spectrum Disorder. Impact. The College of Education and Human Development, University of Minnesota. https://ici.umn.edu/products/impact/193/193. pdf. Accessed 20 Aug 2018.

5. American Association of Poison Control Centers Annual Report. 2016. https://piper filecamp.com/1/piper/binary/2ok6-0gpifoud.pdf. Accessed 20 Aug 2018.

6. Roberts, J. R., Dawley, E. H., \& Reigart, J. R. Children's low-level pesticide exposure and associations with autism and ADHD: a review. Pediatr. Res. 2018. https://www. nature.com/articles/s41390-018-0200-z. 